\title{
Vulnerability, Adaptation and Climate Disasters: A Conceptual Overview
}

\author{
Farhana Yamin, Atiq Rahman and Saleemul Huq*
}

\section{Introduction}

2005 is a landmark year for climate change and for development. Hyogo, ${ }^{1}$ Kyoto $^{2}$ and Gleneagles ${ }^{3}$ have given their names to major frameworks of action aimed at reducing climate-related vulnerabilities and poverty over the coming decade. International efforts to re-orientate policy and institutional structures towards achievement of the Millennium Development Goals ${ }^{4}$ (MDGs) and to secure fairer trade as part of the Doha Development Agenda will also be strengthened in 2005. After the media headlines have faded, what impact will these frameworks have on the lives of the poor and others vulnerable to climate impacts? Will climate vulnerabilities be integrated in all these frameworks with lasting benefits? Will the interests and voices of those vulnerable to impacts be heard? Why are MDGs, climate change and trade processes running in parallel tracks? And what can be done to link these processes synergistically in favour of those vulnerable to climate change?

These questions were central to the Linking Climate Adaptation (LCA) Project that aimed to ensure that poor people benefit from adaptation processes, rather than bearing greater burdens by, for example, having the risks caused by climate change shifted in their direction. The key research aim of the LCA Project was to determine what kind of procedural and institutional frameworks are needed to ensure that locally determined adaptation needs are linked "upwards" to national and international policy and institutional structures. Local determination of needs is important because adaptation is highly context specific, and generic policies for successful adaptation are difficult to define. Procedural and institutional frameworks are important because they help define which actors, funding flows and types of policy must be linked to support successful community-led adaptation. At issue in the LCA Project was whether frameworks related to poverty reduction, vulnerability/risk reduction or climate adaptation, or some combination of these, should form the key point of support for community-led efforts to address the impacts of climate change.

The overview element of this article brings together policy relevant insights for these complex questions from the outputs of the project which are set out in this IDS Bulletin: the country case studies and synthesis, the articles on the future climate research agenda and the rationale and plans for the LCA Network that aims to link adaptation policy makers, practitioners and communities impacted by climate. The conceptual aspect of this overview explains why we focused on particular research questions, how we defined key concepts and what underlying theoretical traditions and bodies of evidence we draw upon to support our work. One of the benefits of all the high-level political attention climate change has received in 2005 is the acceptance by a much wider community of development actors that they need to think anew about climate change in preparation for more intensive future actions. By making the values, assumptions, gaps and priorities embedded in our work more accessible we hope our work will prove useful to others embarking on fresh analytical and policy journeys.

Our conclusions, explained in detail below are:

- climate change is a serious, ongoing threat to development and will add burdens to those already poor and vulnerable;

IDS Bulletin Vol 36 No 4 October 2005 (C) Institute of Development Studies 
- climate vulnerability analysis should be incorporated systematically into the three main policy and institutional frameworks relevant for adaptation: development, disaster relief and climate change;

- These three domains should be linked more closely in policy and institutional terms. In policy terms they should share an overarching goal: reduction of climate change-related vulnerabilities;

- Institutional and epistemic linkages should be strengthened with the climate change regime playing a catalysing, bridging role aiming to reorientate development and disaster relief towards tackling the structural causes of vulnerabilities;

- Communities must take centre stage in conducting vulnerability analysis and institutional support should be provided to support their agency in forward implementation efforts to enhance their long-term capacities for adaptation.

\section{Vulnerability and adaptation 2.1 Climate change and development ${ }^{5}$}

Climate change is occurring and is widely recognised to be a serious risk to development (IPCC 2001; Sperling 2003). The impacts of climate variability, manifested in floods, droughts, unseasonal rains and extreme events, create enormous developmental challenges for developing countries and the poorest communities due to their dependence on climate sensitive economic sectors, such as rain-fed agriculture, and their limited economic, technological and human capacities (IPCC 2001a). As a result developing countries and poor communities experience disproportionately high levels of death, social disruption and economic damage. Climate change will multiply these burdens (Sperling and Szekely 2005).

Unfortunately, current development policies, plans and programmes are not well attuned to existing climate vulnerabilities let alone sufficient for increased levels of risks and new risks, such as sea level rise, posed by climate change (Burton and van Aalst 2004). In many cases, development is actually contributing to climate change - through increased greenhouse gas (GHG) emissions from carbon-intensive developmental pathways (Yamin 2004) and through broader processes of change that are increasing vulnerabilities through a variety of socio-economic, political, environmental and cultural factors (Barrow 2003). Because the magnitude of current variability and additional climate risks on development is so large and pervasive, mainstreaming current and future climate vulnerabilities into development is an urgent prerequisite for sustainable development for developing and developed countries alike (Huq et al. 2003; UNDP 2005; Yamin 2005 forthcoming). This can be done by reducing emissions of GHG thus lessening the chances of climate change occurring (mitigation of climate change). It can also be done through enhancing mechanisms that promote planned and unplanned actions to resist, cope and take advantage of unavoidable changes (adaptation to climate change).

\subsection{Community-led adaptation}

The LCA Project focused on the second strategy adaptation - with the focus on adaptation efforts led by communities affected by climate impacts. Definitions of community tend to centre on whether people are subject to a "local administrative unit" or belong to cultural, ethic or regionally defined group (Leach et al. 1997). We defined the concept of community by reference to people subject to a local administrative unit because the focus of the LCA Project was on how different groups of people at different scales of governance might organise around climate impacts and be supported in their proactive efforts to adapt in respect of a common climate impact or threat. By focusing our definition of community on regions where groups of people identified themselves as sharing a common climatic past and future destiny, we were able to examine many different kinds of communities of relevance to climate policy, ranging in size from a few hundred people to several million (Huq et al., this IDS Bulletin).

Communities are not homogenous. Sharing climate impacts or threats does not imply that each member of the community is affected in the same way as all others. Whether small or large, communities are highly differentiated in terms of access to resources and factors such as age, gender, class and ethnicity and these differences are highly significant to the vulnerability and adaptive capacity of particular individuals. Where possible, LCA case study authors have tried to highlight these differentiations but more detailed work on understanding intra-community vulnerability dynamics is something that will have to be taken forward in other projects. 


\section{Figure 1: Linkages for Supporting Community-led Adaptation}

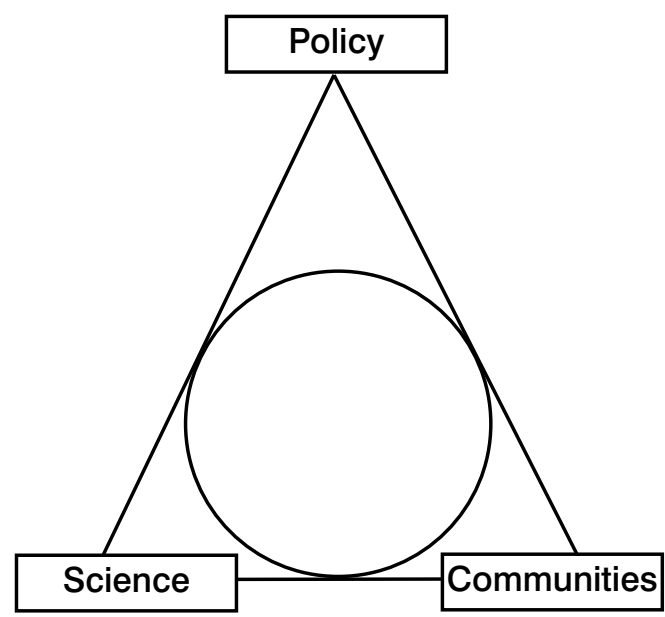

The rationale for centring our analysis on communities was twofold. First, human societies have adapted to climate variability and other changes for millennia and much of the knowledge is embedded in the fabric of social structures operating at the community level. This knowledge is highly relevant for climate adaptation and provides an important supplementary source of expertise to the information generated by more formal scientific institutions and processes. Second, understanding and strengthening the agency of communities is imperative as much adaptation will be undertaken at the local level. Unfortunately, national and international policy are not good at reaching the poor and vulnerable and when they do, tend - unhelpfully at times - to plan interventions "for" communities instead of supporting initiatives led by them.

A key assumption is that support for communities by national and international structures is necessary, not least because communities can reproduce or entrench vulnerabilities. Overly romantic notions of communities as hermetically sealed social units free of "outsiders" and untainted by "international" processes that can cope with climate change if left to their own creative devices do exist. All the communities studied under the LCA Project were examples of "glocal" spaces - geographically distinct but constituted, in part, by context specific as well

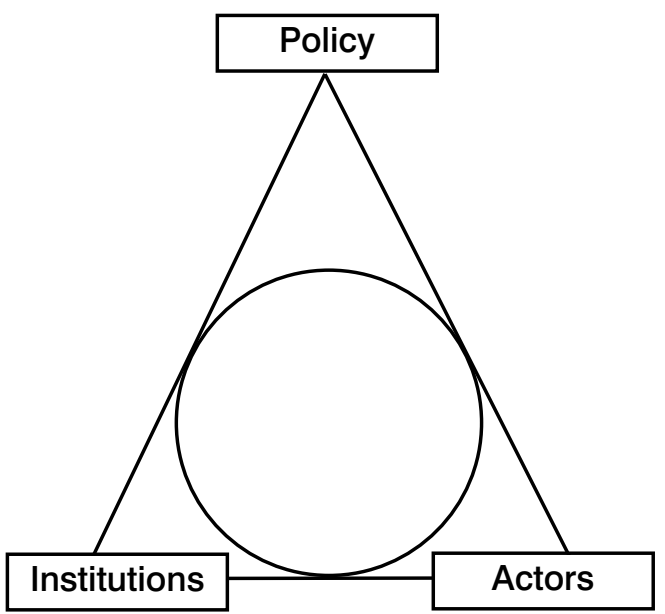

as global processes (Harcourt and Escobar 2002). Some institutional and coping capacity existed in all communities; none could cope entirely on their own without external support of some kind. Whilst traditional knowledge provides a base from which to learn, it is based on information about past climate, and this may provide insights that do not correspond with future challenges given the scale of changes predicted by climate scientists.

For all these reasons communities need to be linked "upwards" to national and international policy structures that can support adaptation to climate change. Because knowledge of future climate change resides mainly in formal scientific structures, such as the Intergovernmental Panel on Climate Change (IPCC) and national scientific academies, communities also have to be linked to such knowledge structures. These linkages are illustrated in Figure 1.

\subsection{Defining vulnerability and adaptation}

As the LCA Project was concerned with adaptation to climate impacts by vulnerable communities, a key conceptual issue was what we meant by vulnerability and how this was linked to poverty and coping strategies.

Writing in an IDS Bulletin on vulnerability and how the poor cope, Robert Chambers' 1989 editorial introduction began by noting that "vulnerable" and "vulnerability are common terms in the lexicon of 


\section{Box 1: Approaches and Definitions of Vulnerability and Adaptation}

The concept of "vulnerability" and the related terms "coping", "resilience" and "adaptation" are used in different ways by different disciplines and policy communities (IPCC 2001; Füssel and Klein 2002; O'Brien 2004; Easterling 2004; Moench and Dixit 2004; Adger et al. 2004; Wisner et al. 2004).

Natural hazards and disasters approaches focus on hazards and the dose-exposure of affected communities to identify impacts and hazard-related vulnerabilities. This view focuses on factors such as the frequency (or probability), intensity and nature of the physical hazard as key components of vulnerability and the exposure of communities to such hazards. Less attention is paid to existing vulnerabilities and the role of socio-economic conditions and power relations in structuring such vulnerabilities in particular distributive configurations. A merit of this approach is the clear significance attached to infrequent but extreme events and the focus on delineating hazard-specific vulnerabilities.

An alternative view, described as the social vulnerability approach, starts by assessing vulnerabilities already embedded in the social and political order. Vulnerabilities therefore exist prior to and independently of hazards. People's coping strategies and socio-economic structures are put centre stage. Social vulnerability approaches tend to treat the vulnerability environment as "given." But this underplays the role of hazards, particularly infrequent ones, in generating and perpetuating vulnerabilities. One implication is the shift in policy attention away from macro level causes of hazards, shock and stresses - that might be reduced at the macro level through disaster mitigation, preparedness and risk reduction - towards more micro level processes. Another is that people are labelled as "vulnerable" and seen as "victims", forever trying to cope with problems.

Integrative approaches to vulnerability come from climate change research which sees vulnerability as a function of the character, magnitude, and rate of climate variation to which a system is exposed, its sensitivity, and its adaptive capacity (IPCC 2001: 995; for a discussion of the internal consistency of this definition see Füssel and Klein 2002). The state of the art integrative approach to vulnerability comes from the disaster community and is set out in the Hyogo Framework 2005-2015 adopted by the UN in 2005. Vulnerability is defined as 'the conditions determined by physical, social, economic and environmental factors or processes, which increase the susceptibility of a community to the impact of hazards.' Hazards are defined as 'a potentially damaging physical event, phenomenon or human activity that may cause the loss of life or injury, property damage, social and economic disruption or environmental degradation.' Hazards can include latent conditions that may represent future threats and can have natural origins or be induced by human processes. The Hyogo definition of "resilience" refers to "the capacity of a system, community or society potentially exposed to hazards to adapt by resisting or changing in order to reach and maintain an acceptable level of functioning and structure. This is determined by the degree to which the social system is capable of organising itself to increase this capacity for learning from past disasters for better future protection and to improve risk reduction measures.' This incorporates the concept of "coping" which usually connotes temporary measures designed to maintain or return to the status quo and the concept of "adaptation" which refers to learning from the past to make improvements from changing circumstances.

development, but their use is often vague', pointing out that often these terms simply serve as convenient substitutes for "poor" and "poverty." He sought to distinguish poverty which he defined as 'deprivation, lack or want' from vulnerability, described as 'defencelessness, insecurity, and exposure to risk, shocks and stress' (Chambers 1989). We believe the distinction between poverty and vulnerability highlighted by Chambers is an important one. Vulnerability is not poverty: vulnerability is shorthand for factors that drive people into poverty, keep them in poverty and block their exit routes from poverty (ActionAid 2005).

The concept of vulnerability is valuable because it draws attention to the multiple dimensions of deprivation, such as social exclusion and gender, as well as to poverty dynamics and to established patterns of coping and resilience used by those directly affected. Understanding vulnerability should deepen our understanding of the climatic, social, generational, geographic, economic and political processes that generate poverty, particularly chronic 
poverty. The latter has been neglected in poverty analysis but is of particular relevance for climate policy because climate impacts have the potential to create large regional poverty traps, if as predicted, impacts strike successive generations of vulnerable groups repeatedly over extended time frames.

Although Chamber's definition, and underlying social vulnerability approach it encapsulates, has been influential in development, it is not the only way of approaching vulnerability. A conceptual mapping exercise for the Human Dimensions of Global Environmental Change Programme undertaken this year found no consensus definition of vulnerability and no agreed approach to its operationalisation in social science literature (Schoon 2005). This gives the impression that little progress has been made before and since 1989 on tackling vulnerabilities. We believe leaving the story there would be a misleading account of conceptual and practical developments to date as well as those on the horizon.

Other disciplines have offered rich insights complementing social vulnerability perspectives about the nature of "vulnerability" and the related terms "resilience" and "adaptation". There is, in addition, now a vast social science literature on the concept of "risk", some of which is closely related to the notion of "hazards" and thus of relevance to environmental decision making under uncertainty (Stirling 2003; Mehta et al. 2001). In the LCA Project, we focused on approaches and definitions found in climate change, natural hazards and social vulnerability literature, as these streams are conceptually and operationally clearly linked to poverty reduction and disaster risk reduction. An overview of the main approaches and definitions is set out in Box 1.

\subsection{Conceptual and operational developments in vulnerability}

In surveying conceptual and operational developments relating to vulnerability in the field of climate change, development and disaster relief, we found cause for despondency and for optimism. Despondency because, whilst progressive inroads have been made in the field of development to incorporate vulnerability (such as through adoption of the sustainable livelihoods framework discussed below), it would be fair to say that mainstream development approaches still neglect vulnerability. The focus of attention remains poverty reduction with poverty defined mainly in monetary metrics and policy interventions focused on improving incomes.

An important conclusion from the LCA Project was that today's poverty is yesterday's unaddressed vulnerability. Climate variability and extreme events play a large role in the "basket" of vulnerabilities faced by the poor due to their disproportionate dependence on natural resource-based livelihoods and location at high-risk of natural disasters. Fresh research on vulnerability - who is vulnerable, to what risks, and why and how this links with climate vulnerability - particularly from the perspective of communities themselves - could play an important role in re-orientating development policy and researchable questions elaborating on these issues (Yamin, Mitchell and Tanner, this IDS Bulletin).

Different vulnerability approaches used by various policy communities and disciplines contribute analytical strengths that can help identify causal connections and policy linkages which a single approach may leave unexposed. We believe that combining insights and linking practitioner expertise from related fields, rather than championing one particular approach and one particular set of developmental actors, might help tackle the "distressingly limited" integration of risk/vulnerability analysis with poverty analysis confirmed in the LCA case studies and pointed out by many others (Barrett and McPeak 2004; Sperling and Szekely 2005).

The survey of approaches to vulnerability resulted in some good news to balance the despondency. A much wider constellation of academic, policy and advocacy groupings from the development, humanitarian relief and climate change fields are now interested in pooling their analytical and policy work on vulnerability. The growing recognition within these three fields about the centrality of vulnerability, the conditions and factors that give rise to it and how it is linked to, but separate, from poverty, is to be welcomed. As is the widespread recognition within each that much less time should be spent on yesterday's sterile debates focused on arguing about the respective contributions of the natural and social sciences, and much more on integrating the predictive power of natural sciences, with understandings of how human societies have been shaped as much by their environments as by their conceptions of "nature" and have coped with change through constructing an array of complex social, economic and political institutions. 
Of course, conceptual approaches and terminological differences among and between disciplinary and policy boundaries on vulnerability and society-nature relationships still abound. Some differences are healthy and we can expect these to continue. But some result from factors that are not obvious. Increased pressures to boost research assessment ratings and generate funding within academia and development think tanks can, for example, lead them to exaggerate differences to champion their own "brand" of research and policy tools over competing "brands". It is also important to factor in that critique has also become a fashionable end in itself in some development circles as a result of postmodernism and post-structuralism trends in social science research (Cooper and Packard 1997).

The conceptual domain is an important battleground but looking at emergent practices for clues about the direction of progressive developments on the ground is also important. Academic research lags behind shifts in policy and their impacts. In many cases then, practise generates more fundamental conceptual developments (although it is a conceit of academics to think otherwise). More and more development nongovernmental organisations (NGOs) with grassroots bases in developing countries are reporting that communities are aware of the changing climate even if they do not call this "climate change" (Simms and Reid 2005; BCAS 2005). And there is a growing level of practical, operational guidance about how vulnerability analysis can be better integrated, for example in poverty reduction (Hulme and McKay 2005) sustainable livelihoods (Twigg 2001; IISD 2003; Cannon et al. 2004), social protection (Devereux and Sabates-Wheeler 2004; Barrrett and McPeak 2004), climate adaptation planning (UNDP 2005) and disaster risk reduction (ActionAid 2005; Sperling and Szekely 2005).

Incorporation of knowledge from lay and expert perspectives in risk-related decision making is also being accepted more widely as a norm, although not always implemented in the fullest spirit in all spheres, such as economic and trade policy (Munton 2003; Pimbert 2004). And participatory approaches to vulnerability analysis and disaster risk reduction policy, though still in their early stages, are beginning to emerge (e.g. see ActionAid 2005). Collectively, these developments create the possibility of communities affected by climate change having a much greater say in national and international policy for climate adaptation and, by implication, broader social, economic and political issues inevitably raised by climate change.

\section{Policy and institutional frameworks \\ 3.1 Understanding policy processes}

Turning that possibility into reality, however, requires an understanding of the nature of policy processes. As conceptualised in Figure 1, policy results from the interplay of actors, institutions, political and power dynamics and conceptual "framings" that structure and determine what is considered (ir)relevant, (un)important and (im)practical.

Policy processes aimed at securing human wellbeing are institutionally fragmented and dysfunctional for tilting power in favour of social and economic justice (Allot 1990, 2002). For many developing countries, financial, economic and trade policy is determined, in large part, by the Bretton Woods Institutions (BWIs), the World Trade Organization (WTO) and transnational corporate actors using narrowly defined framings of wellbeing. These processes and players generate wealth but also embed structural vulnerabilities in the social and economic order. Dealing with inequalities and the impacts of vulnerabilities is left to a vast array of national, regional and international institutions with weak legal mandates ill-matched to challenge and create alternative forms of peoplecentred development. The result is uncoordinated development and disaster relief efforts that duplicate or cut across each other, in ways that waste aid (Archarya et al. 2004, privileges donors, and the epistemic communities that support them, in defining "good" development for others (Eyben 2003; Chambers 2005), and leaves the poor and vulnerable exposed to a wide range of long-term threats, shocks and surprises.

In this fragmented institutional (dis)order, where should those interested in community-led adaptation focus their policy efforts? Climate change negotiations? Poverty Reduction Strategy Papers (PRSPs) and national sustainable strategy plans? Development of national platforms for disaster risk reduction under Hyogo? Should they eschew international processes altogether in favour of contesting public policy from below (Cornwall 2004)? 


\section{Box 2: Policy and Institutional Frameworks Guiding Development}

Mainstream development is defined by efforts to reduce poverty on the one hand and to boost economic growth on the other. Both are defined and measured largely in monetary terms, privileging the expertise of economics and of international economic institutions such as the World Bank. Markets, not states, are the primary engine for growth which should be fostered through "good" governance. Poverty and vulnerability are seen, under this approach, essentially as transitory phenomenon that can be overcome, in the long term, by properly functioning markets and governance and, in the short term, by targeted poverty reduction measures in the form of monetary transfers, "safety nets" or "trampolines" that catch or bounce poor people out of poverty. Climate adaptation, including to disasters, would in this view be taken care of largely by economic growth, better governance and humanitarian efforts.

Basic needs/human development approaches critique mainstream development for not taking into account that economic growth does not always improve key education, health or social welfare outcomes which are essential for people to develop. Development should therefore focus, not just on boosting incomes but on meeting common universal basic "needs" such as food, water, housing, health care, education, safe work and environment, and physical and economic security (Doyal and Gough 1991). The human development approach focuses on securing "well-being" or "human development" as the ultimate end, rather than on the commodities or means (income, food, housing etc.) to achieve these ends (Sen 1999; Haq 1995; Nussbaum 2000). Unlike previous approaches, human development approaches stress non-material aspects, such as autonomy, security and friendship, make more use of concepts from moral philosophy and ethics than economics, and allow for different cultures and peoples to specify their developmental needs (Hulme and McKay 2005; Chambers 2005).

Rights-based approaches (RBAs) also aim to put human beings centre stage but are more focused on requiring developmental efforts to be pinned down to the achievement of fundamental rights such as those enshrined in international human rights standards (IDS 2005; VeneKlasen et al. 2004).

Sustainable livelihoods (SL) approaches have been adopted by many development agencies and NGOs (Scoones 1998; Carney 1999, 2002). These arose from dissatisfaction with top down, narrowly defined poverty reduction efforts which ignored the different resources rural poor people used to stay out of poverty and failed to take into account the complex interplay between these strategies and local institutional and social factors. The SL framework provides a holistic tool to identify how a wide range of assets are used in multiple ways by individuals and households in developing countries to deal with insecurity, shocks and external stresses. SL approaches put people at the centre of development, within a context of external vulnerability due to (i) long-term and large-scale trends (e.g. population, technological and resource trends), (ii) shocks (e.g. epidemics, natural disasters, economic shocks such as sudden exchange rates), and (iii) seasonality (seasonal shifts in prices, production, food availability and employment and health).

To answer these questions, we looked for insights from law, politics and international relations, particularly from recent research on different types of policy processes that have deployed a family of approaches based on "actor-orientated network theory". This provides a useful framework to study how and why certain framings, interests and actors come to prevail, taking into account social, political and institutional factors that operate at different scales and macro-micro linkages between levels (Callon and Law 1989; Latour 1994). Research using these approaches now covers a broad range of policy processes, including environmental policy processes (Steins 2001; Keeley and Scoones 2003), global economic, trade and business regulation (Braithwaite and Drahos 2000), and international law and politics (Reus-Smit 2004). The problem is that climate change is neither an "environmental" 
problem or an "economic" one, nor one simply about the realpolitik of collective action: it incorporates dimensions of all three. It is the mix of three that makes it unique and an exciting testing ground for the emergence of new approaches to broader issues of global governance (Hain 2001; Kjellen 2004; Kanie and Haas 2004).

Nevertheless, research on environmental policy process, global economic regulation and international politics proved useful for illuminating aspects of national and international climate change policy processes. Collectively the body of research on different types of policy processes bears out the general conclusion that ideas that win out are not necessarily the best intellectually but those which command the political attention, and fit the bureaucratic scheme, or those with influence in policy circles. Even then, the need for "buy in", by countries, agencies and affected communities, necessitates a degree of constructive ambiguity. Keeping this ambiguity open in favour of the poor and marginalised requires constant policy vigilance as policy processes are social construction, open to the ebb and flow of politics, with gains once made subject to reversals. An additional important insight from this research is that those with influence in policy processes may be traditional actors such as economically powerful states, corporations and expert communities. But they can also be influential individuals or NGOs that act as "issue champions" and are able to "enrol" others to their point of view due to their charisma, sound organisational skills and ability to translate ideas with widespread appeal from one policy domain to another. The concept of "social entrepreneurship" has been used to describe such issue champions when there is explicit attention to the poor or vulnerable.

\subsection{Competing policy and institutional frameworks}

The political, policy and advocacy resources of the poor cannot take on the vast agenda implicated in the prevention of climate change and adaptation to its consequences in one bite. Cutting the agenda into "bite" size pieces makes the challenge more comprehensible and manageable. The issue remains: which actors, institutions and ideas must be challenged, and which enlisted, to support community-led adaptation? The institutional fragmentation symptomatic of development means there are so many ideas jostling for policy attention, it is difficult to keep track. The essences of some approaches to development are outlined in Box 2, together with the "framing" implications they carry for climate adaptation.

Our main conclusion in the LCA Project was that as things currently stand, none of the approaches is sufficient, on its own and without modifications, to match the challenge of climate change adaptation which is linked to the broader challenge of sustainable development. Poverty reduction/ economic growth approaches fail to take vulnerabilities, particularly risks relating to longterm environmental degradation, into account. Incorporation of environmental externalities through market-based mechanisms or economic valuation techniques is at an early stage and needs to be more widespread to make a positive impact on sustainable resource use. The basic needs/human development approaches provide an important normative framework to guide international efforts to achieve development but have proved difficult to operationalise and their contribution to development remains more powerful in normative than in practical terms. Rights-based approaches (RBAs) have only recently been adopted by some development agencies and NGOs, so the extent to which these can secure long-term changes in the distribution of economic resources and political power remains to be seen and is already being questioned in some circles (Nyamu-Musembi and Cornwall 2004).

Sustainable livelihood approaches present the most useful starting point for analysis and policy work related to integration of climate vulnerabilities. Their strengths lie in their aim to empower people in terms of analysis and participation as well as bridging the gap between micro- and macro-level factors and actions by analysing how people engage in transforming structures and policy processes (Twigg 2001). It is important to note, however, they have been trialled mostly in rural agricultural contexts which are fast changing in most developing countries. Because the different weight different types of assets (economic, natural, social, human and political) should carry is not agreed upon, and they are fundamentally incommensurable, their contribution to the sustainable part of sustainable development also remains contested. Additionally, sustainable livelihoods (SL) approaches could lead to analysis that neglects the role of infrequent, but extreme, events which are likely to increase in severity, frequency and geographic range with climate 
change with major changes to entire regions and economies. Finally, their strength in linking micromacro aspects requires lengthy analysis and dependence on external facilitators which practitioners have found to be time-consuming (Carney 1999; Twigg 2001).

Promoting community-led adaptation will therefore require conceptual development as well as the rapid operationalisation of new ways to incorporate vulnerabilities and the perspectives of communities into relevant policy processes.

\section{Conclusions and recommendations for linking policy and institutional frameworks}

The main conclusion from the LCA Project is that a long-term joint overarching objective should be agreed for climate change, development and disaster relief policy. This objective should focus on the reduction of climate-related vulnerabilities using approaches of different groups of people to make preventative- and preparedness-related decisions that reduce their individual and collective vulnerabilities, whilst also enabling them to achieve well-being and sustainable development.

Supporting community-led adaptation means putting communities centre stage in determining which vulnerabilities are addressed and how they are to be reduced: it also means giving communities the central role in implementation and monitoring and evaluation of end results. Because the magnitude, geographic scale and ongoing long-term nature of climate hazards necessitates addressing the structural causes of vulnerability that cannot be addressed in a piecemeal, project-by-project fashion, the focus of community-led adaptation should be on contributing to a broad range of policy processes. This requires linking communities to scientific and technical networks that support policy making in ways that enable communities to participate more effectively in national and international policy processes.

Which policy processes might help achieve these goals? Climate change, development and disaster relief seemed to us the three most logical places to start the "bite" size work. Linking these processes through agreement on the overarching goal of vulnerability reduction, rather than identifying one institutional basket, in which all the well-being eggs must be laid, is a more effective (and less risky) route for achieving more "enrolment" for vulnerability reduction efforts. Linking need not involve the creation of a new international agency to exercise coordination. It could be done more effectively through promoting denser conceptual and practitioner level linkages among and between key players, such as the three expert or "epistemic communities" involved in the three processes. The creation of more effective physical and virtual learning "spaces" of the kind spelt out in the article on the LCA Network might also provide a practical step forward (Yamin et al., this IDS Bulletin). However it occurs, such a reorientation will require changes in policy, institutional and funding arrangement in all three domains. Details of some specific suggestions are spelt out below.

\subsection{Development and disaster relief}

Development assistance currently amounts to around $\$ 55-60$ billion annually, a much larger sum compared with the \$3-6 billion available for 2002-6 for climate and other global environmental issues. But much development work and related funding does not incorporate climate and other natural hazard risks. In some cases development contributes to making people more vulnerable. Recent reviews of PRSPs indicate they do not take environmental considerations into account (Bojo and Reddy 2002) and do not often recognise natural hazards (Burton and van Aalst 2004). Most development practitioners see climate risks and natural hazards as exogenous, "one-off" events that should be dealt with, if and when they actually lead to disaster, through humanitarian relief rather than through "normal" development (DFID 2005). The number of disasters and losses is rising (Sperling and Szekely 2005). Disaster relief costs, currently around $\$ 6$ billion annually from donors, are also rising (DFID 2005). Yet it has been estimated that for every $\$ 1$ spent on preparing for a disaster, a further \$4-10 is saved in the costs of recovering from it (Tearfund 2005 forthcoming).

The rationale for linking disaster relief and development was compellingly put forward a decade ago (Maxwell and Buchanan-Smith 1994). But powerful legal, institutional and political obstacles stand in the way of making disaster relief more development orientated, in particular of shifting from disaster management to disaster preparedness and risk reduction frameworks - as demonstrated by the Kenya and Bangladesh case studies (Orindi et al.; Mallick et al, this IDS Bulletin). A more systemic incorporation of current and future 
climate-related vulnerabilities would make all the development frameworks set out in Box 2 much more cost effective, in particular by releasing flows now tied up in "emergency" disaster work as well as diminishing anxiety that climate-related disasters will swallow ever larger shares of development assistance.

A shift in orientation towards vulnerability reduction for the disasters community would require rebalancing funding away from emergency disaster relief and reconstruction in favour of disaster prevention. To achieve this, the disasters community needs to focus mainly on issues of governance and sustainability, as repeated rounds of short-term "emergency" intervention can weaken long-term institutional structures and foreclose sustainability options (see Orindi et al., this IDS Bulletin).

A vulnerability perspective on chronic poverty would suggest research to identify risk-bearing burdens attached to different kinds of assets used by the poor because even where the risk never materialises, bearing risk burdens is very real and costly-especially in cases where there are critical, irreversible thresholds facing the poor (Barrett and McPeak 2004). One implication is that poverty reduction efforts should be supplemented with a broader range of instruments to remove noneconomic risks that make people vulnerable to poverty as suggested by many studies (Devereux and Sabates-Wheeler 2004; Wisner et al. 2004; Barrett and McPeak 2004; Hulme and Mckay 2005).

\subsection{Climate change policy}

The challenge for the climate regime is to catalyse a wider range of policy and institutional frameworks to take the climate adaptation agenda forward, rather than trying to do it all by itself. Conceptually and institutionally, it is in a strong position to catalyse work by other agencies and actors. Vulnerability and adaptation to adverse impacts are an integral part of the UNFCCC and Kyoto. The ultimate objective of both instruments is, after all prevention of dangerous human interference with the climate system - a goal which sits comfortably with development and disaster risk reduction perspectives. The UNFCCC also contains extensive provision relating to vulnerability, including, for example, reduction of emissions to lessen the chances of adverse climate change as well as mandatory provisions for richer countries to provide resources for developing countries vulnerable to adverse impacts to adapt to climate impacts (Yamin and Depledge 2004).

By providing a strong multilateral institutional framework backed by law, the climate regime has greater potential to provide a more transparent, participatory and accountable forum for catalysing structural changes needed to engage the efforts of powerful actors in vulnerability reduction. Poverty reduction and disaster relief frameworks by contrast lack this connection as both are grounded in disparate institutional processes defined by donor-dominated humanitarian conceptions of development and subject to the politics of aid.

Institutionally, it is also important to remember that climate change currently has less "bite" in finance and national developmental ministries. But this might change: Hurricane Katrina looks set to change perspectives with early indications of losses and costs amounting to $\$ 100$ billion. The climate regime also has less conceptual and political baggage and therefore more capacity for policy and institutional creativity than other policy frameworks (Yamin and Depledge 2004). This capacity that has defied predictions from traditional realist and alternative constructivists perspectives alike, who have produced extensive analysis demonstrating why the Protocols should not exist, and failed to explain why it has entered into force against the wishes of the most powerful (Grubb and Yamin 2001). From the perspective of poor and vulnerable communities, who are often marginalised in policy-making processes, the climate change process is also by far the most open and dynamic multilateral process in town - with powerful lobbies in developed countries and increasingly in developing countries emerging to catalyse progressive change across a wide spectrum of actors, such as coalitions of marginalised countries supported by NGOs and civil society.

Collectively these policy and institutional considerations make climate change a bridgebuilding process that could make the most of the conceptual and practical tools developed to date by others whilst maintaining its distinctive identity and more limited purpose and supporting broader processes intended to achieve developmental wellbeing. Of course, this is not to say that changes are not needed in the climate change regime to support community-led adaptation. Funding and resources to support a much wider basket of actions related to adaptation than is currently the practise under the "incremental cost" approach must be provided 
urgently (Huq et al. 2003). And funding project cycles also need to change to support small-scale, community-led projects integrating multiple benefits for climate change, biodiversity and natural resource management which often lose out to largescale, single-sector projects.

\subsection{Conclusions}

The LCA Project was one recent initiative amongst many in 2005, all confirming that global development itself cannot be achieved unless the underlying factors that generate climate-related vulnerabilities are tackled. The gap between this recognition and practical efforts has been highlighted in the past but the threat of climate change means it must be bridged swiftly if people are to be protected and development itself "climate proofed". This requires putting the interests of communities and their understanding of vulnerabilities centre stage. It also requires linking policy domains that now run in parallel tracks with each other, in ways that synergise their efforts and achieve more effective use of development resources.

Too often research projects end with a list of further questions that merit research. We did not do that. Rather we ended the project with the realisation that social ideals and possibilities for the

\section{Notes}

The authors wish to thank Martin Greeley and Robert Chambers for helpful comments on earlier drafts of this overview and also Melissa Leach and Ian Scoones for their advice on setting up the LCA Project.

1. Hyogo Framework for Action 2005-2015: Building the Resilience of Nations and Communities to Disasters, A/CONF.206/6, World Conference on Disasters Reduction, 18-20 January, Kobe, Hyogo, Japan.

2. 1997 Kyoto Protocol to the UN Framework Convention on Climate Change (UNFCCC). The Protocol entered into force on 16 February 2005 and has been ratified by 153 parties. Its sets target GHG reductions for industrialised countries covering the 2008-12 period.

3. G8 Gleneagles Summit Agreement and Plan of Action: Climate Change, Clean Energy and Sustainable future become trapped within policy and institutional structures - structures that divide and disable the achievement of collective goals. Structures we created and have the power to recreate. 2005 has provided a remarkable opportunity to exercise that power. Gleneagles, the Make Poverty History Campaign, agreements at Hyogo and the entry into force of the Kyoto Protocol strengthened our conviction that if we link our efforts, we can align policy and institutional structures to secure the goal of developmental wellbeing for all in the face of climate change.

Hurricane Katrina impacts in the USA reminded us that climate change is a global threat to the wellbeing of all - but especially the poor and the vulnerable, wherever they are. By allowing us to engage more deeply in examining the nature of this challenge, the LCA Project proved to us that it is well within the collective grasp of all those involved in climate change, development and disaster relief, to follow through on the conceptual and practical alignment necessary to achieve that goal. It will take time, conviction, further resources and of course, the efforts of many others to recognise the challenge and to see merit in linking climate adaptation with their work.

Development. The Summit "package" aims to "green" the $\$ 26$ trillion worth of energy investment expected over the next 25 years as well as to launch a dialogue to address commitments by major emitters beyond the 2012 period Under a separate agreement which will have major implications for Africa's climate vulnerabilities, the G8 Summit also agreed the biggest aid deal in history for Africa, to double development aid by $\$ 48$ billion by 2010 and to write off debt initially for 18 African countries.

4. In Larger Freedom: Towards Development, Security and Human Rights For All, Report of the UN Secretary-General, A/59/2005, 21 March 2005

5. For a fuller discussion of the science, impacts and policy linkages between climate change and development, see 'Climate Change and Development', IDS Bulletin, Vol 35 No 3, July 2004, available through IDS. 
IDS Bulletin 36.4 Vulnerability, Adaptation and Climate Disasters

\section{References}

ActionAid, 2005, Participatory Vulnerability Analysis: A Step by Step Guide for Field Staff, London: Action Aid International, International Emergencies Team Allot, P., 2002, The Health of Nations, Society and Law Beyond the State, Cambridge: Cambridge University Press

Allot, P., 1990, Eunomia, New Order for a New World, Oxford: Oxford University Press

Archarya, A., Fuzzo de Lima, A. and Moore, M., 2004, 'The proliferators: transaction costs and the value of aid', IDS Working Paper 21, Brighton: Institute of Development Studies

Barrett, C. and McPeak, J., 2004, Poverty Traps and Safety Nets, Ithaca: Cornell University

Barrow, C.J., 2003, Environmental Change and Human Development, Controlling Nature?, New York: Arnold

BCAS, 2005, Report on Community Level Adaptation,

Bojo, J. and Reddy, R.C., 2002, Poverty Reduction Strategies and Environment: A Review of 40 Interim and Full Poverty Reduction Strategy Papers, Washington, D.C.: World Bank

Braithwaite, J. and Drahos, P., 2000, Global Business Regulation, Cambridge: Cambridge University Press

Brooks, N., Kelly, M., et al., 2004, New Indicators of Vulnerability and Adaptive Capacity, Norwich: Tyndall Centre for Climate Change Research

Burton, I. and van Aalst, M., 2004, Look Before You Leap: A Risk Management Approach for Incorporating Climate Change Adaptation into World Bank Operations, Washington, D.C.: World Bank

Callon, M. and Law, J., 1989, 'On the construction of sociomaterial networks: Content and context revisited', Knowledge and Society: Studies in the Sociology of Science Past and Present, Vol 8: 57-83

Cannon T., Twigg, J. and Rowell, J., 2004, Social Vulnerability, Sustainable Livelihoods and Disasters, London: DFID

Carney, D., 2002, Sustainable Livelihoods: Approaches, Progress and Possibilities for Change, London: Department for International Development

Carney, D., 1999, Livelihood Approaches Compared, London: Department for International Development

Chambers, R., 2005, Ideas for Development, London: Earthscan

Chambers, R., 1989, 'Editorial introduction: vulnerability, coping and policy', IDS Bulletin, Vol 20 No 2
Cooper, F. and Packard, R., 1997, 'Introduction', International, Berkeley: University of California Press

Cornwall, A., 2004, 'New democratic spaces? The politics and dynamics of institutionalised participation', IDS Bulletin, Vol 35 No 2

Devereux, S. and Sabates-Wheeler, R., 2004, 'Tranformative social protection', IDS Working Paper 232, Brighton: Institute of Development Studies

DFID, 2005, Disaster Risk Reduction: A Development Concern, London: Department for International Development, Conflict and Humanitarian Affairs Department

Doyal, L. and Gough, I., 1991, A Theory of Human Needs, Basingstoke: Macmillan

Easterling, G., 2004, 'Climate adaptation in the USA', Pew Paper, Washington, D.C.

Eyben, R., 2003, 'The rise of rights, rights based approaches to international developments', IDS Policy Briefing 17, Brighton: Institute of Development Studies

Füssel, H. and Klein, R., 2002, 'Assessing Vulnerability and Adaptation to Climate Change: An Evolution of Conceptual Thinking', paper presented at the UNDP Expert Group Meeting on 'Integrating Disaster Reduction and Adaptation to Climate Change', Havana, Cuba, 17-19 June, available from Potsdam Institute for Climate Impact Research, Germany

Grubb, M. and Yamin, F., 2001, 'Climate collapse at The Hague: what happened, why and where do we go from here?', International Affairs 2

Hain, P., 2001, Redefining Foreign Policy, The End of Diplomacy, London: Fabian Society

Harcourt, W. and Escobar, A., 2002, 'Women and the politics of place', Development, Vol 45 No 1, Basingstoke: Palgrave Macmillan: 7-14(8)

Haq, M., 1995, Reflections on Human Development, Oxford: Oxford University Press

Hulme, D. and McKay, A., 2005, 'Identifying and understanding chronic poverty: beyond monetary measures', zero order draft, 11 June, Chronic Poverty Research Centre, University of Manchester and University of Bath

Huq, S., Rahman, A., Konate, M., Sokona, Y. and Reid, H., 2003, Mainstreaming Adaptation to Climate Change in Least Developed Countries, London: International Institute for Environment and Development 
IDS, 2005, 'Developing rights?', J. Pettit and J. Wheeler (eds), IDS Bulletin, Vol 36 No 1, Brighton: Institute of Development Studies

International Institute for Sustainable Development (IISD), 2003, 'Livelihoods and Climate Change: Combining Disaster Risk Reduction, Natural Resource Management and Climate Change Adaptation in a New Approach to the Reduction of Vulnerability and Poverty', a conceptual framework paper prepared by the Task Force on Climate Change, Vulnerable Communities and Adaptation

IPCC, 2001, Third Asssessment Report, Cambridge: Cambridge University Press

IPCC, 2001a, Synthesis Report, Third Assessment Report, Geneva: Intergovernmental Panel on Climate Change

Kanie, N. and Haas, P., 2004, Emerging Forces in Environmental Governance, Tokyo: UNU Press

Keeley, J. and Scoones, I., 2003, Understanding Environmental Policy Processes, London: Earthscan

Kjellen, J., 2004, 'Pathways to the future, the new diplomacy for sustainable development', IDS Bulletin, Vol 35 No 3

Latour, B., 1994, Science in Action: How to Follow Scientists and Engineers Through Society, Cambridge: Harvard University Press

Leach, M., Mearns, R. and Scoones, I., 1997, 'Community-based sustainable development, consensus or conflict?', IDS Bulletin, Vol 28 No 4

Maxwell, S. and Buchanan-Smith, M., 1994, 'Linking relief and development: introduction and overview', IDS Bulletin, Vol 25 No 4

Mehta, L., Leach, M. and Scoones, I. (eds), 2001, 'Environmental governance in an uncertain world', IDS Bulletin, Vol 32 No 4

Moench, M. and Dixit, A. (ed.), 2004, Adaptive Capacity and Livelihood Resilience: Adaptative Strategies for Responding to Floods and Droughts in South Asia, Nepal: Institute for Social and Environmental Transition, International, Boulder and Institute for Social and Environmental Transition

Munton, R., 2003, 'Deliberative Democracy and Environmental Decision-Making', in F. Berkhout, M. Leach and I. Scoones, Negotiating Environmental Change, Cheltenham: Edward Elgar

Nussbaum, M., 2000, Women and Human Development: The Capabilities Approach, Cambridge: Cambridge University Press
Nyamu-Musembi, C. and Cornwall, A., 2004, 'What is the rights-based approach all about? Perspectives from international development agencies', IDS Working Paper 234, Brighton: Institute of Development Studies

O’Brien, K., Eriksen, S., Schjolden, A. and Nygaard, L.P., 2004, 'What's in a word? Conflicting interpretations of vulnerability in climate change research', CICERO Working Paper

Pimbert, M., 2004, 'Natural resources, people and participation', Participatory Learning and Action 50, London: International Institute for Environment and Development

Reus-Smit, C. (ed.), 2004, The Politics of International Law, Cambridge: Cambridge University Press

Schoon, M., 2005, 'A short historical overview of the concepts of resilience, vulnerability and adaptation', Working Paper W05-4, Workshop in Political Theory and Political Analysis, Indiana University

Scoones, I., 1998, 'Sustainable rural livelihoods: a framework for analysis', IDS Working Paper 72, Brighton: Institute of Development Studies

Sen, A., 1999, Development as Freedom, Oxford: Oxford University Press

Simms, A. and Reid, H., 2005, Africa: Up in Smoke, London: International Institute for Environment and Development/NEF

Sperling, F., (ed.), 2003, Poverty and Climate Change, Washington, D.C.: Vulnerability and Adaptation Resource Group

Sperling, F. and Szekely, F., 2005, 'Disaster risk management in a changing climate', Discussion Paper, prepared for the World Conference on Disaster Reduction on behalf of the Vulnerability and Adaptation Resource Group

Steins, N., 2001, 'New directions in natural resource management: the offer of actor-network theory', in L. Mehta, M. Leach and I. Scoones (eds), 'Environmental governance in an uncertain world', IDS Bulletin, Vol 32 No 4

Stirling, A., 2003, 'Risk, Uncertainty and Precaution: Some Instrumental Implications from the Social Sciences', in F. Berkhout, M. Leach and I. Scoones (eds), Negotiating Environmental Change: Some Perspectives from Social Sciences, Massachusetts: Edward Elgar

Tearfund, 2005 (forthcoming), Mainstreaming Disaster Risk Reduction Within Institutions Donors: Performance Targets and Indicators, London: Tearfund 
IDS Bulletin 36.4 Vulnerability, Adaptation and Climate Disasters

Twigg, J., 2001, Sustainable Livelihoods and Vulnerability to Disasters, London: Benfield Greig Hazard Research Centre

UNDP, 2005, Adaptation Policy Frameworks for Climate Change: Developing Strategies, Policies and Measures, B. Lim (ed.), Cambridge: UNDP and Cambridge University Press

VeneKlasen, L., Miller, V., Clark, C. and Reilly, M., 2004, 'Rights-based approaches and beyond: challenges of linking rights and participation', IDS Working Paper 235, Brighton: Institute of Development Studies

Wisner, B., Blaikie, P., Cannon, T. and Davis, I., 2004 (2nd ed.), At Risk: Natural Hazards, People's
Vulnerability and Disaster, London and New York: Routledge

Yamin, F., 2005 (forthcoming), 'The European Union and future climate policy: is mainstreaming adaptation a distraction or part of the solution?', Climate Policy

Yamin, F. (ed.), 2004, 'Overview of climate change and development', IDS Bulletin, Vol 35 No 3: $1-19$

Yamin, F. and Depledge, J., 2004, 'Taking Stock and Moving Forward', in The International Climate Change Regime, Ch. 19, Cambridge: Cambridge University Press 